\title{
Evaluation of the effect of synbiotic in piglets' diet on the nutritional quality of pork
}

\author{
Mihaela Saracila *, Arabela Elena Untea, Tatiana Dumitra Panaite \\ *corresponding author: mihaela.saracila@ibna.ro
}

National Research and Development Institute for Biology and Animal Nutrition, 077015 Ilfov, Romania

\section{ABSTRACT}

The purpose of the study was to increase the nutritional quality of pork, and to investigate the effect of the synbiotic on the oxidative stability of lipid. A 4 weeks experiment was performed on 8 weaned piglets (age 47 days, TOPIGS), divided into 2 groups (C, E). The control group (C) received a conventional diet, while the experimental group (E) included a diet supplemented with organic $\mathrm{Zn}$ and $10 \mathrm{~g} / \mathrm{kg}$ synbiotic mixture. The productive parameters were evaluated. After slaughtered, muscle (tenderloin, shoulder, loin, ham and belly) and organs samples (liver, spleen and kidney) were collected. The muscle and organs samples were analysed regarding the proximate chemical analysis (dry matter, crude protein, crude fat, and ash). The antioxidant capacity and thiobarbituric acid reactive substances (TBARS) were performed on shoulder and ham samples at first day of the trial, 4 and 7 days after refrigeration. The crude fat determined in the loin samples, recorded a significant increase in the $\mathrm{E}$ group compared to the $\mathrm{C}$ group. The ash was higher in the shoulder samples from $C$ group than in E group. At 7 days of refrigeration, the MDA concentration was significantly lower in the shoulder and ham samples from $E$ group than those from $C$ group. The conclusion was that the diet supplemented with organic $\mathrm{Zn}$ and $10 \mathrm{~g} / \mathrm{kg}$ synbiotic mixture contributed to the delay of the lipid oxidation process of the shoulder and ham samples during the refrigeration period.

Keywords: synbiotic, organic zinc, pigs, nutritional quality, pork

\section{INTRODUCTION}

The piglets are predisposed to different bacterial or non-bacterial diseases. But the excessive use of antibiotic growth promoters in animal husbandry has resulted in the evolution of resistance pathogens (Begum et al., 2018). Thus, in this context the development of other additive alternatives in 
animal nutrition is needed. Further, from the consumer point of view, the meat quality is an important attribute. Some parts of pork contain high level of fat; thus, the lipid oxidation imposes a serious problem mainly during the storage period causing meat quality deterioration and accumulation of several harmful products (Popova, 2017).

The synbiotics (mixtures of probiotic and prebiotic) can be considered an effective natural feedstuff, with benefits on host animal. They can bring better balance of gastrointestinal tract and by selectively stimulating the favorable growth of health-promoting bacteria (Hume, 2011).

Previously published studies conducted on pigs have demonstrated that the supplementation of synbiotic with different components promotes body weight gain and feed conversion ratio (Shim et al., 2005), improves intestinal morphology (Duarte et al., 2020), modulates intestinal microflora composition (Shim et al., 2005), etc. The meat obtained from piglets fed prebiotics like inulin improved the quality properties of meat (Grela et al., 2021).

The use of different probiotics and prebiotics in the monogastric diet reduced lipid oxidation in meat by inhibiting the formation of thiobarbituric acid reactive substances (TBARS) (Popova, 2017; Dev et al., 2020).

The synbiotics are a combination of probiotic and prebiotic approaches, which may give the synergistic effects of both prebiotics and probiotics on the growth of pigs (Shim et al. 2005; Lee et al. 2009). The synergistic effects are due to the ability of prebiotics to enhance the survival and multiplication of probiotics (Alloui et al., 2013; Markowiak, and Śliżewska, 2017).

The purpose of the study was, on the one hand, increasing the nutritional quality of pork, but also to investigate the potential positive effect of the synbiotic (a combination of ingredients with synergistic action, having four active components: probiotic "Enterococcus faecium"; prebiotic "fructooligosaccharides - inulin"; cell walls and phycophytic substances such as seaweed extracts) on the oxidative stability of lipids.

\section{MATERIALS AND METHODS}

The experiment was performed on a number of 8 weaned piglets (age 47 days), males, castrated hybrid TOPIGS (Large White $\times$ Hybrid (Large White $\times$ Pietrain). The experiment lasted 4 weeks preceded by 4 days of accommodation and the gradual introduction of experimental feed in animal feed. The piglets were divided into 2 groups (C, E), with 4 animals per group, kept in individual metabolic cages (Agrico, Rybarska, Czech Republic). The control group (C) received a conventional diet. The diet of group E consisted in a diet with the same basic structure as that of group $\mathrm{C}$, but the mineralvitamin premix was supplemented with organic Zn (E.C.O. Trace ${ }^{\circledR}$ Trace minerals, Biochem Zusatzstoffe Handels- und Produktions gesellschaft mbH 
Küstermeyerstr, Germany) and $10 \mathrm{~g} / \mathrm{kg}$ synbiotic mixture (BiominR IMBO Pro/prebiotic, BIOMIN, GmbH Austria) (Table 1).

Table 1. Diet formulation

\begin{tabular}{lcc}
\hline \multicolumn{1}{c}{ Ingredient } & C & E \\
\hline Maize & 35.70 & 35.69 \\
Wheat & 26.00 & 26.00 \\
Rice & 9.00 & 9.00 \\
Corn gluten & 3.00 & 3.00 \\
Soybean meal & 17.30 & 17.30 \\
Sunflower meal & 4.00 & 4.00 \\
Feed concentrate* & 5.00 & 5.00 \\
Synbiotic & - & 0.01 \\
Chemical composition & \multicolumn{2}{|c}{} \\
Metabolisable energy (Kcal/Kg) & \multicolumn{2}{c}{3129.60} \\
Dry matter (\%) & \multicolumn{2}{c}{18.59} \\
Crude protein (\%) & \multicolumn{2}{c}{1.65} \\
Crude fat (\%) & \multicolumn{2}{c}{4.12} \\
Crude fiber (\%) & \multicolumn{2}{c}{} \\
\hline
\end{tabular}

* Feed concentrate contains: $11.90 \%$ soybean meal, $7.20 \%$ lysine, $1 \% \mathrm{Dl}$ - methionine, $36 \%$ calcium carbonate, $18 \%$ mono calcium phosphate, $4 \%$ salt, $20 \%$ premix (for $\mathrm{E}$ diet, the premix was supplemented with organic $\mathrm{Zn}$ ), $2 \%$ choline

Throughout the experimental period, the body weight and feed intake were recorded and the productive parameters (average daily gain, feed conversion) were calculated. At the end of the experiment, all pigs were slaughtered and muscle tissues (tenderloin, shoulder, loin, ham and belly) and organs samples (liver, spleen and kidney) were collected. The samples were distributed for drying in order to perform the proximate chemical analysis (dry matter, DM\%; crude protein, CP\%, crude fat, EE\% and ash, Ash). The CP, $\mathrm{EE}$ and Ash content of the pork samples were determined according to Regulation (CE) no. 152/2009 (Methods of sampling and analysis for the official inspection of feeds).

Based on the fact that shoulder and ham are the cuts of meat with intramuscular fat, those samples were selected to perform the methods on oxidative stability. For this, the samples were kept in the fridge at $4{ }^{\circ} \mathrm{C}$ until chemical analysis.

Total antioxidant capacity (TAC) of the pork samples was evaluated by the phosphate- molybdenum method of Prieto et al. (1999), with some modifications as described by Untea et al., (2018). The results were expressed as mmol AA equivalent / kg dry weight (DW). 
Thiobarbituric acid reactive substances (TBARS) values were determined using third derivative spectrophotometry with some modifications as described by Untea et al., (2020). TBARS were expressed as milligrams of malondialdehyde (MDA) per kg of sample.

Data are expressed as mean \pm standard error of the mean (SEM). The statistical analysis was performed using analysis of variance (ANOVA) with STATVIEW for Windows (SAS, version 6.0). The differences between mean values in the groups were considered significant at $\mathrm{P}<0.05$.

\section{RESULTS AND DISCUSSION}

Bioproductive parameters did not differ significantly between groups as Untea et al., (2017) described previously. Previous studies reported no influence of dietary symbiotic on growth performance. For example, Cheng et al., (2018) showed that diet supplemented with $1 \mathrm{~g} / \mathrm{kg}$ synbiotic consisted of prebiotics (yeast cell wall and xylooligosaccharide) and probiotics (Clostridium butyricum, Bacillus licheniformis, and Bacillus subtilis) for 21 days did not affect growth performance in late-finishing pigs. In contrast, Balamuralikrishnan et al., (2016) showed that the use of probiotic supplementation in the pigs diet showed significant differences in average daily gain and gain:feed, but no effects on average daily feed intake.

Table 2. Proximate chemical composition of pork samples

\begin{tabular}{|c|c|c|c|c|}
\hline Groups & Dry matter (\%) & $\begin{array}{c}\text { Crude protein } \\
(\%) \\
\end{array}$ & Crude fat (\%) & Ash (\%) \\
\hline \multicolumn{5}{|c|}{$\mathrm{Ham}$} \\
\hline $\mathrm{C}$ & $33.92 \pm 0.87$ & $17.99 \pm 0.37$ & $1.82 \pm 0.18$ & $1.08 \pm 0.08$ \\
\hline $\mathrm{E}$ & $32.86 \pm 0.58$ & $\begin{array}{r}18.11 \pm 0.43 \\
\text { Belly }\end{array}$ & $2.00 \pm 0.83$ & $1.11 \pm 0.03$ \\
\hline $\mathrm{C}$ & $22.55 \pm 0.83$ & $18.04 \pm 0.39$ & $2.81 \pm 0.56$ & $1.02 \pm 0.03$ \\
\hline \multicolumn{5}{|c|}{ Shoulder } \\
\hline $\mathrm{C}$ & $21.84 \pm 0.68$ & $17.99 \pm 0.37$ & $2.65 \pm 0.31$ & $1.09 \pm 0.04 \mathrm{~b}$ \\
\hline \multicolumn{5}{|c|}{$\begin{array}{r}10.11 \pm 0.40 \\
\text { Loin }\end{array}$} \\
\hline $\mathrm{C}$ & $22.34 \pm 0.84$ & $19.82 \pm 0.61$ & $0.95 \pm 0.38^{b}$ & $1.15 \pm 0.03$ \\
\hline \multicolumn{5}{|c|}{ Tenderloin } \\
\hline $\mathrm{C}$ & $19.25 \pm 0.78$ & $17.22 \pm 0.80$ & $1.12 \pm 0.06$ & $1.05 \pm 0.04$ \\
\hline $\mathrm{E}$ & $19.62 \pm 1.15$ & $17.13 \pm 0.94$ & $1.44 \pm 0.44$ & $1.11 \pm 0.04$ \\
\hline
\end{tabular}

Means within a column with no common superscript differ $(\mathrm{p}<0.05)$.

From the data presented in Table 2 it can be seen that there were no significant differences in the chemical composition of the meat, for any of the 
parameters measured except the concentration of crude fat determined in the loin samples, which recorded a significant increase $(\mathrm{p}<0.05)$ in the experimental group compared to the control group. This increase was 3.12 times higher.

From the analyzed samples, a classification from the point of view of the protein content highlights the fact that the loin represents the anatomical part with the highest protein content $(19.82 \pm 0.61 \% \mathrm{CP}-\mathrm{C}$ respectively $19.93 \pm 0.54 \% \mathrm{CP}-\mathrm{E}$ ) and the lowest fat content (Table 2). In contrast, the belly is the anatomical part richest in fat $(2.81 \pm 0.56 \% \mathrm{EE}-\mathrm{C}$ and $2.63 \pm 0.38$ $\%$ EE - E).

Table 3. Proximate chemical composition of selected organs

\begin{tabular}{lcccc}
\hline Groups & Dry matter (\%) & Crude protein (\%) & Crude fat (\%) & Ash (\%) \\
\hline C & $27.94 \pm 0.58$ & $19.16 \pm 0.58$ & $2.91 \pm 0.21$ & $1.34 \pm 0.05$ \\
E & $26.80 \pm 2.18$ & $19.53 \pm 1.50$ & $2.88 \pm 0.22$ & $1.39 \pm 0.11$ \\
& \multicolumn{5}{c}{ Kidney } & & \\
C & $18.92 \pm 0.77$ & $14.79 \pm 0.43$ & $1.78 \pm 0.26$ & $1.13 \pm 0.07$ \\
$\mathrm{E}$ & $19.20 \pm 1.53$ & $14.71 \pm 1.34$ & $2.03 \pm 0.23$ & $1.13 \pm 0.08$ \\
& & Spleen & & \\
$\mathrm{C}$ & $19.57 \pm 1.52$ & $15.75 \pm 1.27$ & $1.61 \pm 0.15$ & $1.31 \pm 0.07$ \\
$\mathrm{E}$ & $19.72 \pm 0.38$ & $15.86 \pm 0.27$ & $1.62 \pm 0.10$ & $1.32 \pm 0.01$ \\
\hline
\end{tabular}

Table 3 shows the results obtained for the proximate chemical composition of the organs collected at slaughter. From the presented data it can be seen that there were no significant differences in content in DM, CP, EE and Ash.

Regarding the antioxidant capacity, the fresh shoulder samples from group $\mathrm{C}$ and $\mathrm{E}$ showed an antioxidant capacity comparable to that of the refrigerated samples (Figure 1). After 4 and 7 days of refrigeration, the antioxidant capacity of pork shoulder samples from group $\mathrm{C}$ did not register significant differences than those from the E group, demonstrating comparable antioxidant properties. Pork ham samples expressed a constant antioxidant capacity during the refrigeration period and there were no significant differences between them and even between the samples at 0,4 and 7 days of refrigeration in group $E$ and those in group C. In contrast, Cheng et al., (2018) demonstrated that dietary synbiotic supplementation to the diet of late-finishing pigs would enhance muscle antioxidant capacity and improve meat quality. 

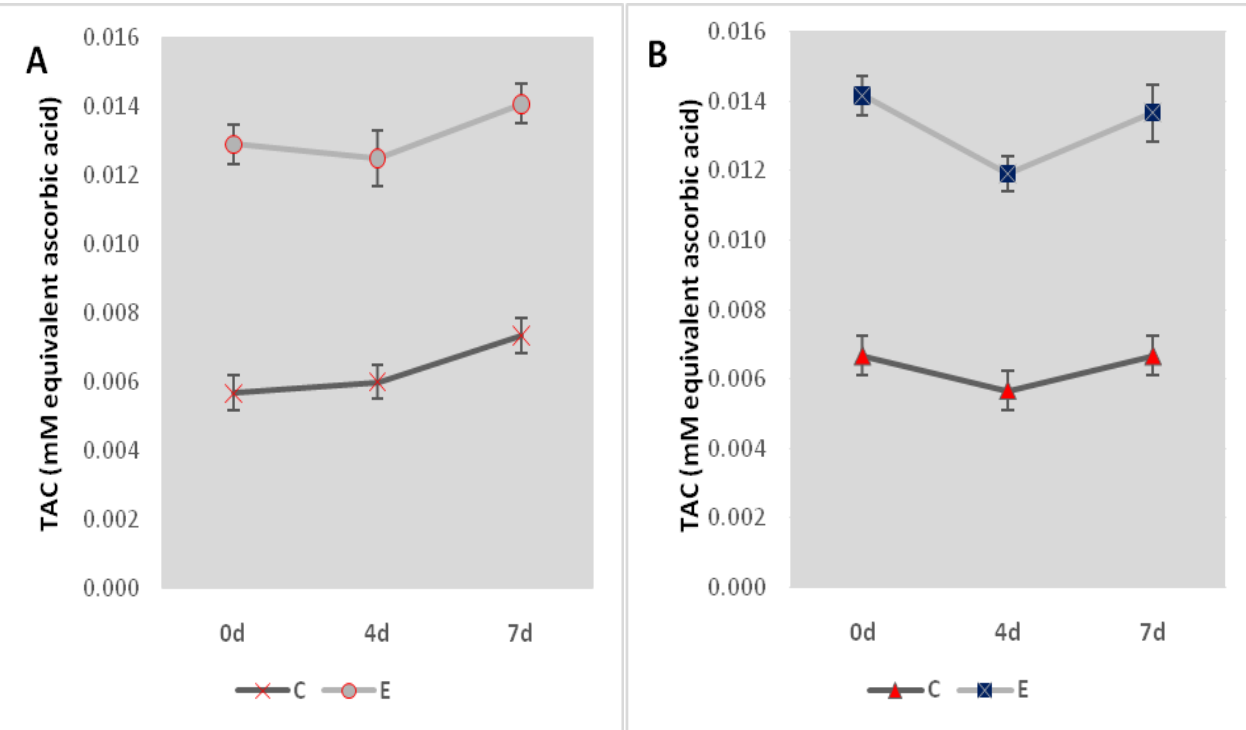

Figure 1. Total antioxidant capacity in pork shoulder (A) and ham samples (B)

In the figure 2, are presented the concentrations of MDA (mg/kg) detected on the pork shoulder and ham samples.
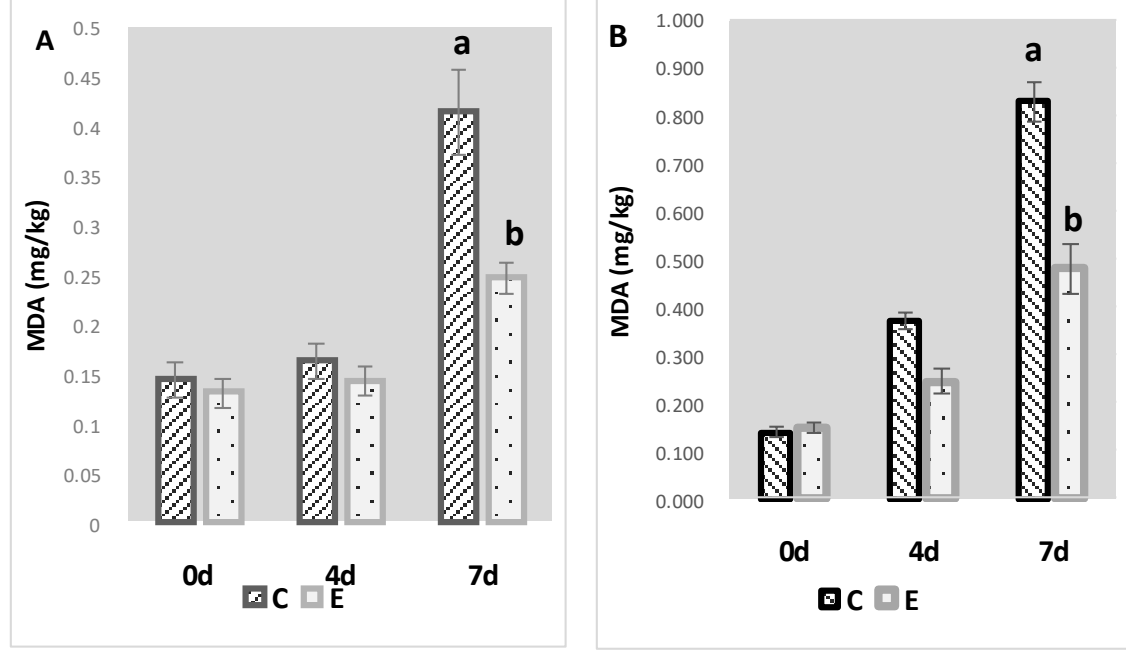

Figure 2. Malonaldehyde concentration (mg/kg MDA) from pork shoulder (A) and ham samples (B)

At 0 and 4 days of refrigeration, the MDA concentration in the shoulder samples did not differ between groups (Figure2). Notably is that at 7 
days of refrigeration, the shoulder samples collected from E group contained a significantly lower level of MDA than those from $C$ group. Thus, the shoulder samples from $\mathrm{C}$ group showed a more accentuated lipid degradation compared to those from E group.

At 0 and 4 days of refrigeration, there were no significant differences between the ham samples from the $\mathrm{C}$ group and those belonging to the $\mathrm{E}$ group. The concentration of MDA in fresh ham samples from the $\mathrm{C}$ group was lower, respectively by $7.91 \%$ compared to those in the E group (Figure 2). After 4 days of storage in refrigeration conditions, the pork ham samples from the E group showed a MDA content lower by $17.43 \%$, compared to the $\mathrm{C}$ group. It is observed that after 7 days, the MDA content increases significantly compared to the other periods, approximately 2 times, compared to the fresh ham samples.

The lipid oxidation process was intensively investigated and it was demonstrated that the storage time and temperature influenced the formation of degradation products such as conjugated dienes and trienes, aldehydes, etc. (Domínguez et al., 2019; Saracila et al., 2020). In the present study, the MDA concentration in the shoulder and ham samples increases in direct proportion with the storage time, the most impressive increase was observed in the 7 th day of refrigeration.

Although the total antioxidant capacity for hydrophilic compounds did not differ significantly between groups (Fig.1), the inhibition of MDA formation (Fig. 2.) was probably due to lipophilic compounds as meat is a fatty matrix.

\section{CONCLUSION}

The results of the study highlighted that dietary synbiotics and organic acids supplements improved the oxidative stability of the pork shoulder and ham at 7 days of refrigeration. Thus, the use of synbiotics and organic acids supplements in the piglet's diet could be an effective nutritional solution to improve the shelf life of pork during refrigeration.

\section{ACKNOWLEDGEMENTS}

This work was funded by the Research, Innovation and Digitization, grant number PN 19090102. 


\section{REFERENCES}

Alloui, M.N., Szczurek, W., Swiatkiewicz, S., 2013. The usefulness of prebiotics and probiotics in modern poultry nutrition: a review/Przydatnosc prebiotykow i probiotykow $\mathrm{w}$ nowoczesnym zywieniu drobiuprzeglad. Annals of Animal Science, 13, 17.

Begum, J., Mir, N.A., Dev, K. and Khan, I.A., 2018. Dynamics of antibiotic resistance with special reference to Shiga toxin-producing Escherichia coli infections, Journal of Applied Microbiology, 125, 1228-1237.

Balasubramanian, B., Li, T., Kim, I.H., 2016. Effects of supplementing growingfinishing pig diets with Bacillus spp. probiotic on growth performance and meat-carcass grade quality traits. R. Bras. Zootec., 45, 93-100.

Cheng, Y.F., Chen, Y.P., Du, M.F., Wen, C., Zhou, Y.M., 2018. Evaluation of dietary synbiotic supplementation on growth performance, muscle antioxidant ability and mineral accumulations, and meat quality in late-finishing pigs. Kafkas Univ Vet Fak Derg. 24, 5, 673-679.

Dev, K., Akbar, Mir N., Biswas, A., Kannoujia, J., Begum, J., Kant, R., Mandal, A., 2020. Dietary synbiotic supplementation improves the growth performance, body antioxidant pool, serum biochemistry, meat quality, and lipid oxidative stability in broiler chickens. Animal Nutrition, 6, 3, 325-332.

Domínguez, R., Pateiro, M., Gagaoua, M., Barba, F.J., Zhang, W., Lorenzo, J.M., 2019. A comprehensive review on lipid oxidation in meat and meat products. Antioxidants 8, 429.

Duarte, M.E., Tyus, J., Kim, S.W., 2020. synbiotic effects of enzyme and probiotics on intestinal health and growth of newly weaned pigs challenged with enterotoxigenic F18+ Escherichia coli. Front. Vet. Sci. $7,573$.

Grela E.R., Swi ‘atkiewicz M., Florek M., B ‘akowski M., and Skiba G., 2021. Effect of inulin source and a probiotic supplement in pig diets on carcass traits, meat quality and fatty acid composition in finishing pigs, Animals, 11, 2438.

Hume, M.E., 2011. Historic perspective: Prebiotics, probiotics, and other alternatives to antibiotics. Poultry Science, 90, 11, 2663-2669.

Lee, S.J., Shin, N.H., Ok, J.U., Jung, H.S., Chu, G.M., Kim, J.D., Kim, I.H. and Lee, S.S., 2009. Effects of dietary synbiotics from anaerobic microflora on growth performance, noxious gas emission and fecal pathogenic bacteria population in weaning pigs, Asian-Aust. J. Anim. Sci. 22, 8, $1202-1208$.

Markowiak, P., Śliżewska, K., 2017. Effects of probiotics, prebiotics, and synbiotics on human health. Nutrients. 9, 1021.

Popova, T., 2017. Effect of probiotics in poultry for improving meat quality. Current Opinion in Food Science. 14, 72-77. 
Prieto, P., Pineda, M., Aguilar, M., 1999. Spectrophotometric quantitation of antioxidant capacity through the formation of a phosphomolybdenum complex: specific application to the determination of vitamin $\mathrm{E}$. Analytical Biochemistry, 269, 2, 337-341.

Saracila, M., Panaite T.D.,Papuc C.P., Predescu C., Untea A., 2020. Dietary phytogenic mixture for broilers reared under thermoneutral and heat stress conditions. Archiva Zootechnica, 23, 101-116.

Shim, S.B., Verstegen, M.W.A., Kim, I.H., Kwon, O.S., Verdonk, J.M.A.J., 2005. Effects of feeding antibiotic-free creep feed supplemented with oligofructose, probiotics or synbiotics to suckling piglets increases the preweaning weight gain and composition of intestinal microbiota. Archives of Animal Nutrition. 59, 6, 419-427.

Untea, A., Lupu A., Saracila M., Panaite T., 2018. Comparison of ABTS, DPPH, phosphomolybdenum assays for estimating antioxidant activity and phenolic compounds in five different plant extracts." Bulletin of University of Agricultural Sciences and Veterinary Medicine ClujNapoca. Animal Science and Biotechnologies. 75, 110-114.

Untea, A.E., Varzaru, I., Panaite, T.D., Gavris, T., Lupu, A., Ropota, M., 2020. The effects of dietary inclusion of bilberry and walnut leaves in laying hens' diets on the antioxidant properties of eggs. Animals. 10, 191. 